\title{
Constraints of Artificial Insemination Service in Selected Districts of Wolaita Zone
}

\author{
Ephrem Takele Menta* \\ Jimma University College of Agriculture and Veterinary Medicine, School of Veterinary Medicine, Jimma, \\ Ethiopia \\ *Corresponding Author: Ephrem Takele Menta, Jimma University College of Agriculture and \\ Veterinary Medicine, School of Veterinary Medicine, Jimma, Ethiopia
}

\begin{abstract}
Cross sectional study was conducted from November, 2010 to March 2011 to assess the Constraints associated with artificial insemination service in four purposively selected districts of Wolaita Zone. A questionnaire survey was conducted on 384 randomly selected household heads. Moreover, five AITs and two liquid nitrogen production center experts were purposely included in the study. According to the study, the major constraints of artificial insemination revealed by farmers were lack of regular and consistent AI service 379 (98.7\%), lack of mobile AI service 363 (94.5\%), lack of weekend AI service 357 (93\%), shortage of AITs 352 (91.7\%), shortage of inputs 273 (71.1\%), absence of private AI service 384 (100\%), lack of awareness training about AI 353 (91.9\%), occurrence of dystocia due to incompatibility of cow's pelvic cavity with calf size $66(17.2 \%)$. The study also showed inappropriate timing of insemination by farmers, i.e. early insemination 187 (48.7\%) and late insemination $128(33.3 \%)$ as a constraint to AI failure. There was a statistically significant difference among the districts $(p<0.05)$ at $95 \%$ confidence interval with respect to the risk factors that included mobile AI service availability, weekends AI service availability, input availability, availability of awareness training, timing of insemination, and occurrence of dystocia associated with AI service. The major constraints of artificial insemination service revealed by AITs were lack of awareness 4 (80\%), inappropriate timing of insemination by farmers 5 (100\%), shortage of inputs 3 (60\%), lack of mobile AI service 4 (80\%), lack of incentives and on-the-job trainings to AITs 5 (100\%), lack of appropriate cooperation among responsible bodies 5 (100\%). Evaluation of technical skill of AITs revealed that one (20\%) of them was technically excellent, two (40\%) were good, and the remaining two (40\%) were poor. There was no statistically significant difference among the districts with respect to all the risk factors used to assess constraints of AI service mentioned by AITs ( $p>0.05)$. The constraints mentioned by liquid nitrogen production center experts were low production capacity of the center due to poor technical performance of the facility and little attention from the regional bureau of agriculture. The retrospective data revealed that areal coverage of AI service is $7-10 \mathrm{~km}$ radius from AI centers which is quite below the demand. It is concluded that the efficiency of AI service in the area is hindered by different constraints. Therefore, responsible bodies must exert their utmost effort to overcome the constraints and ensure reliable and efficient AI service.
\end{abstract}

Keywords: Artificial insemination, Constraints, Wolaita zone, AITs

List of Abbreviations: AI-Artificial insemination, AIT-Artificial Insemination Technician, AITs-Artificial Insemination Technicians, masl-meters above sea level

\section{INTRODUCTION}

Agriculture is the cornerstone of Ethiopian economy employing approximately $85 \%$ of the total population [1]. Livestock production accounts for approximately $30 \%$ of the total agricultural GDP and $16 \%$ of national foreign currency earnings [1]. The total cattle population for the rural sedentary areas of Ethiopia is estimated to be 47.57 million, of which 55.64\% are females [2]. Out of the total female cattle population, only 201,966 (0.42\%) heads are hybrid; and $30297(0.06 \%)$ heads are exotic breeds. Average daily milk production of milking cows is 1.54 liters per cow per day with an average lactation length of 6 months [2]. The total milk production during the year 2007/08 was 3.22 billion liters [2]. Therefore, the genetic improvement endeavor during the last years was very weak indicating the need for immediate action to improve the genetic makeup as well as product and productivity of indigenous cattle. Artificial insemination (AI) is the process by which semen is collected from the 
male, processed and artificially introduced in to the female's reproductive tract for the purpose of conception [3]. It has been most widely used for breeding of dairy cattle and has made bulls of high genetic value available to all [4]. AI makes possible maximum use of superior sires to breed thousands of females. If semen is collected from a bull and diluted, one bull can inseminate thousands of cows [5]. Although artificial insemination has been in operation in Ethiopia for over 30 years, the efficiency and impact of the operation has not been well-documented [6]. Artificial insemination service started in Wolaita area particularly in Wolaita Sodo in 1970 with the establishment of WADU (Wolaita Agricultural Development Unit), the pioneering agricultural institution in the area. Since then, AI is carried out using semen of pure exotic breeds, like Holstein and Jersey [7]. Despite its early commencement, cross and exotic breeds are not adequately and evenly distributed among the society nowadays. Furthermore, their distribution is limited to moist climatic zones of the area. Therefore, the objective of the research was

To assess and identify major constraints of artificial insemination service in the area; and

To recommend the possible solutions that could help in overcoming the constraints.

\section{Materials AND Methods}

\subsection{Description of the Study Area}

The study was conducted in four districts of Wolaita zone namely Sodo Zuria, Boloso Sore, Damot Woide and Humbo. The total area of Wolaita zone is $4471.3 \mathrm{~km}^{2}$. According to zonal statistical data (2010), the total population is $1,721,969$ and population number per kilometer square is 385 .The prevailing production system in the area is mixed crop and livestock production. The latitude, longitude and altitude of the study districts are $6.53^{\circ} \mathrm{N}, 37.47^{\circ} \mathrm{E}$ and 1950 masl for Sodo Zuria; $7.4^{0}$ $\mathrm{N}, 37.39^{\circ} \mathrm{E}$ and 1930 masl for Boloso Sore; $6.49^{\circ} \mathrm{N}, 38^{\circ} \mathrm{E}$ and 1780 masl for Damot Woide; and $6.39^{\circ} \mathrm{N}, 37.49^{\circ} \mathrm{E}$ and 1800 masl for Humbo [8]. Additional background information of the selected districts is presented in table 1 .

Table1. Background information of the study districts

\begin{tabular}{|c|c|c|c|c|c|c|}
\hline \multirow[t]{2}{*}{ District } & \multirow{2}{*}{$\begin{array}{c}\text { DA } \\
(\mathbf{k m})\end{array}$} & \multirow{2}{*}{$\begin{array}{c}\text { Human } \\
\text { population }\end{array}$} & \multirow{2}{*}{$\begin{array}{c}\text { Cattle } \\
\text { population }\end{array}$} & \multicolumn{2}{|c|}{ Average temperature } & \multirow{2}{*}{$\begin{array}{l}\text { AARR } \\
\text { (Mm) }\end{array}$} \\
\hline & & & & Maximum & Minimum & \\
\hline Sodo Zuria & 325 & 182900 & 96980 & 23 & 16 & 1300 \\
\hline Boloso Sore & 300 & 187973 & 73999 & 24.5 & 17 & 1250 \\
\hline Damot Woide & 375 & 150630 & 61300 & 21 & 18 & 1150 \\
\hline Humbo & 355 & 163705 & 59646 & 22 & 18 & 1100 \\
\hline
\end{tabular}

$D A=$ Distance from Addis Ababa $; \mathrm{km}=$ kilometer AAR= Annual Average Rainfall . Mm= millimeter

Source: [8].

\subsection{Study Population}

The study population is represented by farmers and artificial insemination technicians in the respective districts and liquid nitrogen production experts.

\subsection{Study Design}

A cross-sectional type of study supported by questionnaire survey, and observations was carried out from October 2010 to March 2011 in the four selected districts of Wolaita zone included in this study.

\subsection{Sample Size Determination And Sampling Procedures}

Sample size was determined by using the formula below at $95 \%$ confidence interval and $5 \%$ required absolute precision [9].

Total cattle owners $(n)=Z \alpha^{2} * \underline{p(1-p)}$

$\mathrm{d}^{2}$

Where: $\mathrm{p}($ expected prevalence $)=0.5$

$\mathrm{d}$ (required absolute precision $)=0.05$

$\mathrm{Z} \alpha=1.96$

The total sample size was determined to be 384 annd it was fulfilled in this study. In addition, all of the five AITs and two liquid nitrogen production center experts working in the study area were 
purposely included in the study. The four districts, which are the major users of AI service in Wolaita zone, were purposively selected to conduct the study. Moreover, stratified sampling was used to determine the total number of cattle owners for each district while systematic random sampling was used to select farmers within each district. The sample size distribution of districts is shown in table 2 below.

Table2. Sample size distribution of the districts

\begin{tabular}{|c|c|}
\hline District & Sample Size (cattle owners) \\
\hline Sodo Zuria & 115 \\
\hline Boloso Sore & 115 \\
\hline Damot Woide & 77 \\
\hline Humbo & 77 \\
\hline Total & 384 \\
\hline
\end{tabular}

\subsection{Data Collection}

Structured and pre-tested questionnaires were prepared to interview farmers, AITs, and liquid nitrogen production center experts to collect data on the status of AI service and constraints associated with the service. The variables (risk factors) on which information was collected from farmers include: availability of regular and consistent AI service, availability of mobile AI service, availability of weekend AI service, availability of inputs, availability of AITs, availability of private AI service, availability of awareness training, timing of insemination, and occurrence of dystocia case associated with AI service. Additionally, the variables (risk factors) used to collect information from AITs were: method of service delivery, availability of AI inputs, weekend AI service delivery, timing of insemination, dual responsibility, and availability of on-the-job trainings and incentives,. Evaluation of technical skill of AITs was conducted based on their knowledge of signs of estrus (30\%), timing of insemination (30\%), knowledge of semen motility test (20\%), record keeping (10\%), and motivation (10\%). Those AITs with above $85 \%$ score were categorized as "excellent", 71-85\% "very good", $60-70 \%$ "good" and those below $60 \%$ as "poor". During the interview process, every respondent included in the study was briefed about the objective of the study and the questions were presented. Formal discussion was held with each of them for not less than an hour. Moreover, the retrospective data at AI centers is used to determine the radius of AI service coverage and record keeping of AITs.

\subsection{Data Management and Statistical Analysis}

All data were entered in to Ms-Excel spread sheet after completion of data collection. Data analysis was done using SPSS and descriptive statistics was used to summarize the data.

\section{ReSUlts}

Among the farmers who participated in the questionnaire survey, 379 (98.7\%) revealed that they don't get consistent and regular AI service in the respective districts. There was no statistically significant difference ( $\mathrm{p}>0.05)$ among the districts with respect to availability of regular and consistent AI service (table 3).

Table3. Availability of regular and consistent AI service

\begin{tabular}{|c|c|c|}
\hline Regular and consistent AI service & Frequency & Percentage \\
\hline Available & 5 & $1.3 \%$ \\
\hline Not available & 379 & $98.7 \%$ \\
\hline Total & 384 & $100 \%$ \\
\hline
\end{tabular}

Pearson $\chi^{2}=0.338 \quad$ P value $=0.953$

The study also revealed that, 363 (94.5\%) of the respondents do not get mobile AI service while 5.5\% farmers call AITs home based on personal agreement. There was a statistically significant difference $(\mathrm{p}<0.05)$ among the districts with respect to mobile AI service (Table 4).

Table4. Availability of mobile AI service

\begin{tabular}{|c|c|c|}
\hline Mobile AI service & Frequency & Percentage \\
\hline Available & 21 & $5.5 \%$ \\
Not available & 363 & $94.5 \%$ \\
\hline Total & 384 & $100 \%$ \\
\hline
\end{tabular}

Pearson $\chi^{2}=51.96 \quad$ Pvalue $=0.00$

International Journal of Research Studies in Biosciences (IJRSB) 
Additionally, 357 (93\%) of the respondents' revealed absence of AI service on weekends where as the rest $7 \%$ get weekend service based on personal agreement with AITs. Weekend AI service delivery also varied significantly $(\mathrm{p}<0.05)$ among the districts (Table 5).

Table5. Availability of AI service on weekends

\begin{tabular}{|c|c|c|}
\hline Availability of AI service on weekends & Frequency & Percentage \\
\hline Available & 27 & $7 \%$ \\
\hline Not available & 357 & $93 \%$ \\
\hline Total & 384 & $100 \%$ \\
\hline
\end{tabular}

Pearson $\chi^{2}=67.93 \quad$ P value $=0.00$

Similarly, $273(71.1 \%)$ of the respondents explained shortage of liquid nitrogen and other consumable inputs as a constraint to AI service. There was a statistically significant difference $(p<0.05)$ among the districts with respect to input availability (Table 6).

Table6. Availability of inputs

\begin{tabular}{|c|c|c|}
\hline Availability of inputs & Frequency & Percentage \\
\hline Readily available & 111 & $28.9 \%$ \\
\hline Shortage of inputs & 273 & $71.1 \%$ \\
\hline Total & 384 & $100 \%$ \\
\hline
\end{tabular}

Pearson $\chi^{2}=365.21 \quad$ P value $=0.00$

Furthermore, $352(91.7 \%)$ of the respondents revealed that there is shortage of AITs in their respective districts. There was no statistically significant difference ( $>>0.05)$ among the districts with respect to AIT availability (Table 7).

Table7. Availability of AITs

\begin{tabular}{|c|c|c|}
\hline Availability of AITs & Frequency & Percentage \\
\hline Adequately available & 32 & $8.3 \%$ \\
There is shortage & 352 & $91.7 \%$ \\
\hline Total & 384 & $100 \%$ \\
\hline
\end{tabular}

Pearson $\chi^{2}=1.51 \quad$ P value $=0.68$

It was also observed that in all districts, there is no private AI service despite the desire of farmers to use this biotechnology.

Table8. Availability of private AI service

\begin{tabular}{|c|c|c|}
\hline Availability of private AI service & Frequency & Percentage \\
\hline Available & 0 & $0 \%$ \\
\hline Not available & 384 & $100 \%$ \\
\hline Total & 384 & $100 \%$ \\
\hline
\end{tabular}

Moreover, 353 (91.9\%) of the respondents also revealed that no awareness training is delivered concerning AI service while $8.1 \%$ told that they got training delivered with the support of nongovernmental organization. There was a statistically significant difference $(p<0.05)$ among the districts with respect to awareness training (Table 9).

Table9. Availability of awareness training

\begin{tabular}{|c|c|c|}
\hline Awareness training & Frequency & Percentage \\
\hline Available & 31 & $8.1 \%$ \\
\hline Not available & 353 & $91.9 \%$ \\
\hline Total & 384 & $100 \%$ \\
\hline
\end{tabular}

Pearson $\chi^{2}=24.04 \quad$ P value $=0.00$

Additionally, it was revealed that only $69(18 \%)$ of the farmers present their cows on time of standing heat to AI centers. On the other hand, 187 (48.7\%) and 128 (33.3\%) of the farmers bring their cows early before standing heat and late after standing heat respectively resulting in failure of AI. There was a significant variation $(\mathrm{p}<0.05)$ among the districts with respect to timing of insemination by farmers (Table 10). 
Table10. Timing of insemination by farmers

\begin{tabular}{|c|c|c|}
\hline Timing of insemination during estrus & Frequency & Percentage \\
\hline Early & 187 & $48.7 \%$ \\
\hline On time & 69 & $18 \%$ \\
\hline Late & 128 & $33.3 \%$ \\
\hline Total & 384 & $100 \%$ \\
\hline
\end{tabular}

Pearson $\chi^{2}=75.95 \quad P$ Value $=0.00$

Among the respondents, 66 (17.2\%) strongly complained that their cows encountered dystocia during calving due to incompatibility of cows' pelvic cavity with calf size. There is a statistically significant difference $(\mathrm{p}<0.05)$ among the districts with respect to occurrence of dystocia associated with AI (Table 11).

Table11. Occurrence of dystocia associated with AI

\begin{tabular}{|c|c|c|}
\hline Dystocia associated with AI & Frequency & Percentage \\
\hline Occurred & 66 & $17.2 \%$ \\
\hline Not Occurred & 318 & $82.8 \%$ \\
\hline Total & 384 & $100 \%$ \\
\hline
\end{tabular}

Pearson $\chi^{2}=61.14 \quad$ Pvalue $=0.00$

The evaluation of the technical skill of AITs showed that one (20\%) from Wolaita Sodo was technically excellent, two (40\%) from Wolaita Sodo and Boloso Sore were good, and the remaining two (40\%) from Damot Wode and Humbo were poor. There was no statistically significant difference between AITs with regard to technical skill $(\mathrm{p}=0.265)$. With regard to motivation, four $(80 \%)$ of AITs were totally unmotivated in their career as AIT. Consequently, they are academically upgrading in other disciplines unrelated to AI service under self sponsorship. There was no statistically significant difference between AITs with regard to motivation $(p=0.287)$. Additionally all $(100 \%)$ AITs revealed that they do not get adequateon the job academic and motivational training and overtime duty fee. Concerning service delivery, $4(80 \%)$ of them told that they provide stationed service while $1(20 \%)$ of them provide mobile service based on personal consent with the owner $(\mathrm{p}=0.599)$. They explained the reason for this as lack of transport facilities and incentives. Among the AITs, $2(40 \%)$ explained that farmers present cows early before standing estrus and insist on insemination instead of waiting for next estrus period while $3(60 \%)$ explained that cows are presented early before and late after standing estrus resulting in AI failure $(\mathrm{p}=0.172)$. Four $(80 \%)$ among the five AITs included in the assessment said they were not delivering service on the weekend while $1(20 \%)$ AIT delivers weekend service based on personal agreement with the owner $(\mathrm{p}=0.599)$. Three $(60 \%)$ of AITs complained that liquid nitrogen is not readily available while 2 (40\%) AITs have no problem in getting liquid nitrogen $(\mathrm{p}=0.172)$. Furthermore, all $(100 \%)$ AITs said that they do not believe that Wolaita Sodo liquid nitrogen production center is caring out its responsibility properly. Additionally, two (40\%) AITs told that they have dual responsibilities as AIT and as animal health technician and said that this affects their work in artificial insemination $(\mathrm{p}=0.172)$. All $(100 \%)$ AITs also revealed that they do not get necessary supports by the respective district offices of agriculture to perform their duties properly. Furthermore, all (100\%) AITs revealed the major constraints of AI service as lack of awareness, shortage of inputs and transport facilities, inappropriate timing of insemination, lack of mobile AI service, lack of attention and incentives to AITs, and absence of appropriate cooperation and communication among responsible bodies. On the other hand, both $(100 \%)$ of liquid nitrogen production experts told that the center cannot meet the demand of over $130 \mathrm{AI}$ centers in the region including Wolaita zone due to poor technical performance of the liquid nitrogen production facility and little attention from the regional bureau of agriculture. They also put forward that there is no appropriate cooperation among the center and regional bureau of agriculture and other stake holders with regard to AI service.

Moreover, all of the AITs and liquid nitrogen production experts participated in the study confirmed that AI is not doing well in their respective areas due to many hindering factors. Additionally, the retrospective data at AI centers showed that in all districts cattle owners located out of 7-10 km radius from AI centers do not get the service.

The possible solutions suggested by all AITs and liquid nitrogen production experts were establishing an independent authority overseeing the AI sector at regional and zonal level, raising awareness of the 
community through training, encouraging private AI service, devising incentive mechanisms and onthe-job academic and motivational training scheme to AITs to improve the efficiency of the service, cooperation and communication of stakeholders.

\section{DISCUSSION}

The result of assessment indicated that 379 (98.7\%) of farmers who participated in the questionnaire survey do not get consistent and regular AI service and This result is in agreement with findings of Gebremedhin [10] which identified absence of reliable and consistent AI service as a constraint to AI. Furthermore, $363(94.5 \%)$ respondents revealed absence of mobile AI service while $21(5.5 \%)$ call AITs home based on personal agreement. This is a primary drawback of timely insemination of cows on heat and indicates that stakeholders ought to facilitate the preconditions for mobile AI service delivery. There was a statistically significant difference between the districts with respect to mobile AI service $(p<0.05)$. The reason for this is hypothesized to be shortage of liquid nitrogen to top up portable AI container for mobile service. Ninety three percent of the respondents' revealed absence of AI service on weekends where as the rest $7 \%$ get weekend service based on personal agreement with AITs. There was a statistically significant difference between the districts with respect to weekend AI service $(\mathrm{p}<0.05)$. The reason for this is believed to be similar to the above one. Additionally, 273 (71.1\%) complained shortage of AI inputs in their respective districts. There was a statistically significant difference between the districts with respect to availability of inputs $(p<0.05)$. The reason for this is hypothesized to be adequate availability of liquid nitrogen and semen at Sodo Zuria AI center due to its proximity to Wolaita Sodo liquid nitrogen production center. According to the study, $352(91.7 \%)$ farmers also complained that there is shortage of AITs in their vicinity. This indicates that additional AITs should be trained in order to increase AI service coverage and AI centers should be established near the vicinity of farmers.. The study also revealed that 353 (91.9\%) of the farmers do not get awareness training about AI. There was a statistically significant difference between the districts with respect to awareness training $(\mathrm{p}<0.05)$. This difference may be due to occasional delivery of AI awareness training to Sodo Zuria dairy farmers with the support of non-governmental organizations. Among the participants, 187 (48.7\%) of the farmers inseminate their cows early before standing heat while $128(33.3 \%)$ inseminate late after standing heat. This result also agrees with Foote and Sinishaw $[11,12]$ which showed reduced conception following early and late insemination. There is a significant variation $(\mathrm{p}<0.05)$ between the districts with respect to timing of insemination and the reason for this is believed to be due to variation in routine utilization of AI service. Additionally, $100 \%$ of the respondents mentioned absence of private AI service in the area showing that responsible bodies have to work hard to ensure private participation in AI sector. Among the respondents, 17.2\% explained occurrence of dystocia (difficulty of calving) in their AI mated cows due to incompatibility of the size of the calf and pelvic cavity of the cow. Occurrence of dystocia also varied significantly among districts $(\mathrm{p}<0.05)$. The reason for this may be due to difference in technical skill level of AITs with regard to proper selection of local cows prior to insemination. This indicates the need for careful pre-service selection of cows in comparison with the semen to be used for insemination.

The outcome of the assessment of AITs regarding their technical skill showed that one (20\%) AIT is in the category of excellent, the other two (40\%) in good, and the remaining two (40\%) were in poor category. The result of AITs with technical skill in the category of excellent and poor is higher than findings of Gebremedhin [10] which found $10 \%$ for both excellent and poor while the result of AITs with technical skill in the category of good is lower than Gebremedhin [10] which found $56.7 \%$ for good. There is no statistically significant variation between the AITs with respect to technical skill ( $>0.05)$. This result shows that those under the poor category need further technical training to enhance their skill to the desired standard. The study revealed that four AITs (80\%) are not motivated to work as AITs owing to the prevailing constraints. This result also agrees with Gebremedhin [10] which found that $86.67 \%$ AITs are unmotivated in their career as AIT. It is also in agreement with the reports of the field AI service and extension department [13] showing high turnover of AITs. The reason for this is associated with on-the-job training scheme of regional bureau of agriculture that suspended academic upgrading of AITs as well as with lack of incentives. Among the AITs, 2 (40\%) have dual responsibility as AIT and animal health technician with their primary responsibility being animal health service. Those AITs with dual responsibility should be exclusively engaged in AI service as a primary responsibility. Again, it was revealed that all responsible bodies from regional to district level are not giving proper attention to the AI service signaling the need for imperative action 
to realize genetic improvement of cattle in the area. Furthermore, all (100\%) of AITs revealed that the major constraints of AI service were lack of awareness, lack of mobile AI service, lack of attention and incentives to AITs, shortage of AI inputs and transport facilities, inappropriate timing of insemination, lack of private AI service, lack of appropriate cooperation and communication among responsible bodies. This result is in agreement with Gebremedhin, Bekele and Bearden et al [14, 15, and 16]. Both (100\%) of liquid nitrogen production experts told that the center cannot meet the demand of over $130 \mathrm{AI}$ centers in the region due to poor technical performance of the liquid nitrogen production facility and little attention from the regional bureau of agriculture. This indicates that the regional bureau of agriculture needs to establish additional liquid nitrogen manufacturing facility in order to adequately meet the demand of thirteen zones in the region including Wolaita zone. Additionally, the retrospective data at AI centers showed that in all districts cattle owners located out of 7-10 km radius from AI centers do not get the service. This result is lower than Gebremedhin [10] which found $28 \mathrm{~km}$ radius from AI centers. This signals that additional AI centers have to be opened near the vicinity of farmers to increase areal coverage of AI service.

\section{CONCLUSION AND RECOMMENDATION}

The present study revealed that AI service in the area was not a success at zonal or district level during the last years. The major constraints associated with AI service in Wolaita zone include lack of regular and consistent AI service, shortage of inputs, facilities, and AITs, lack of awareness about AI, inappropriate timing of insemination, lack of mobile AI service, absence of private AI service, lack of incentives and on-the-job training to AITs, poor technical skill of AITs, and absence of collaboration and regular communication among district, zonal and regional bureau of agriculture and other stakeholders. Therefore,

$>$ One zonal body responsible for coordination and monitoring of AI service at district level needs to be established;

$>$ Responsible bodies should pay due attention to AI service in the area;

$>$ Adequate training should be delivered in order to enhance awareness of the society about AI;

Additional AI centers must be established near the vicinity of farmers and mobile and weekend AI service has to be launched.

Additional AITs should be trained in proportion to the demand of community for the service;

AI service delivery should be highly sensitive to the breed improvement programs of the area;

Production capacity of liquid nitrogen production center must be boosted and additional liquid nitrogen production center must be established in order to meet the liquid nitrogen demands of AI centers;

Incentive mechanism and on-the-job training scheme should be devised to improve technical skill and efficiency of AITs and minimize their high turnover; and

$>$ Further study should be conducted to find out other factors hindering efficiency of artificial insemination service.

\section{REFERENCES}

[1] Lobago, F. (2007): Reproductive and Lactation Performance of Dairy Cattle in the Oromia Central Highlands of Ethiopia with Special Emphasis on Pregnancy Period. Doctoral thesis, Swedish university of agricultural sciences, Uppsala.

[2] CSA, central statistics Agency, Federal Democratic Republic of Ethiopia (2008): Agricultural sample survey 2007/8, volume II, Report on livestock and livestock characteristics. Statistical Bulletin 417. Addis Ababa, Ethiopia. Pp 9-10; 26.

[3] Edwards, J. (2010): Artificial insemination of cattle. Available at: www.biotopics.com.uk/ edexcell/ biotechnol/artins.html. Accessed 25th, October 2010.

[4] Johonson, P. (2010): Artificial insemination in cattle. Available at: www.BUZZLE.com/articles/artificialinsemination-in-cattle.html. Accessed October 25, 2011.

[5] Meeske, R. (2010): Artificial insemination. Available at: www.esenberg.com/info/isl/093.html. Accessed 26 th October 2010.

[6] Himanen, A. and Tegegn, A. (1998): A proposal for Establishment of a National Milk Recording and Herd Registration Scheme in Ethiopia. Ministry of agriculture, Addis Ababa, Ethiopia. 
[7] WSCBMC, Wolaita Sodo Cattle Breeding and Multiplication Center (2004):Artificial Insemination in Wolaita zone. Pp 2

[8] WZFEDD, Wolaita zone Finance and Economic Development Main Department (2010): Statistical data of Wolaita Zone in 2010. Pp 6-13

[9] Thrusfield, M. (2005): Veterinary epidemiology. $3^{\text {rd }}$ ed. Black well science Ltd., Oxford, Great Britain. Pp. 182-198.

[10] Gebremedhin, D. (2008): Assessment of problems/constraints associated with artificial insemination service in Ethiopia. MSc thesis, Addis Ababa University Faculty of Veterinary Medicine, Debrezeit Ethiopia.

[11] Foote, RH (1979): time of insemination in dairy cattle. J. Dairy. Sci.29:556.

[12] Sinishaw W. (2005): Study on semen quality and field efficiency of artificial insemination bulls kept at the national AI center. MSc. thesis, Addis Ababa University, Faculty of Veterinary Medicine, Debre Zeit, Ethiopia.

[13] FAISEETD, Field AI service Extension and Training Department, NAIC (2007): Millennium report. National AI center, Addis Ababa, Ethiopia.

[14] Gebremedhin, D. (2005): All in one: Practical Guide to Dairy Farming. Agri-service Ethiopia printing unit, Addis Ababa. Pp. 15-21.

[15] Bekele T. (2005): Calf Sex Ratios in Artificially Inseminated and Natural Mated Female Crossbred Dairy Herd. In: proceedings of the 13th annual conference of the Ethiopian Society of Animal Production. Addis Ababa, Ethiopia, Pp. 225-230.

[16] Bearden H.J., Fuquary, J.W., Willard, S.T. (2004): Applied Animal Reproduction. 6th ed. Mississippi State University. Pearson, Prentice Hall. Upper Saddle River, New Jersey 07458. Pp. 155

[17] Sukmaraga H, Wallinga J.H, Werimon J.M, Winantea A, Bakker H (1982): Factors affecting dystocia and birth weight in Grati cattle $n$ Pujon ,East Java

Citation: Ephrem Takele Menta, "Constraints of Artificial Insemination Service in Selected Districts of Wolaita Zone" International Journal of Research Studies In Biosciences (Ijrsb), Vol. 7, no. 3, pp. 36-43, 2019. http://Dx.Doi.org/10.20431/2349-0365.0703005

Copyright: (C) 2019 Authors. This is an open-access article distributed under the terms of the Creative Commons Attribution License, which permits unrestricted use, distribution, and reproduction in any medium, provided the original author and source are credited. 